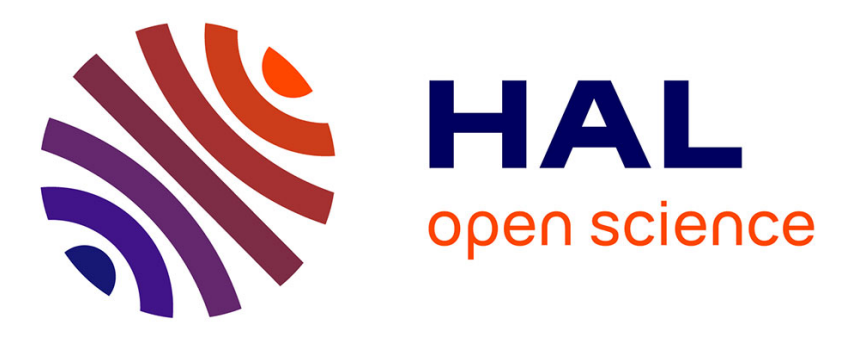

\title{
Study of the self-association of molecular tweezers bearing two different arms: influence of the stereoelectronic effects of the arm substituents
}

Béatrice Legouin, Arnaud Bondon, Clement Orione, Solenn Ferron, Philippe Uriac

\section{To cite this version:}

Béatrice Legouin, Arnaud Bondon, Clement Orione, Solenn Ferron, Philippe Uriac. Study of the selfassociation of molecular tweezers bearing two different arms: influence of the stereoelectronic effects of the arm substituents. Journal of Inclusion Phenomena and Macrocyclic Chemistry, 2020, 96 (1-2), pp.101-109. 10.1007/s10847-019-00954-2 . hal-02391901

\section{HAL Id: hal-02391901 \\ https://hal-univ-rennes1.archives-ouvertes.fr/hal-02391901}

Submitted on 13 Feb 2020

HAL is a multi-disciplinary open access archive for the deposit and dissemination of scientific research documents, whether they are published or not. The documents may come from teaching and research institutions in France or abroad, or from public or private research centers.
L'archive ouverte pluridisciplinaire HAL, est destinée au dépôt et à la diffusion de documents scientifiques de niveau recherche, publiés ou non, émanant des établissements d'enseignement et de recherche français ou étrangers, des laboratoires publics ou privés. 


\section{Study of the self-association of molecular tweezers bearing two different arms: influence of the stereoelectronic effects of the arm substituents.}

Béatrice Legouin, ${ }^{\mathrm{a}}$ Arnaud Bondon, ${ }^{\mathrm{a}}$ Clément Orione, ${ }^{\mathrm{b}}$ Solenn Ferron, ${ }^{\mathrm{a}}$ and Philippe Uriac ${ }^{\mathrm{a}}$

${ }^{a}$ Univ Rennes, CNRS, ISCR-UMR 6226, F35043 Rennes, France; ${ }^{b}$ SCANMAT, F35042 Rennes, France.

Corresponding author beatrice.legouin@univ-rennes1.fr, Phone +33 223234809 iD 0000-0003-4402-6184

Abstract

In the general field of molecular recognition, the self-assembly of a tweezer bearing a $\mathrm{R}(+)$ usnic acid arm and a substituted 1,8-naphthalimide moiety as a second arm was investigated through a ${ }^{1} \mathrm{H}$ NMR study. Two self-association modes were evidenced: either the usnic acid arms (mode A) or the naphthalimide ones (mode B) were face to face in the center of the dimer. The existence of a third non-symmetrical mode (mode $\mathrm{C}$ ) has not been evidenced experimentally. The behavior of these tweezers was discussed taking into account the electronic density of the naphtalimide arms and the slow mode A/mode B exchange rate (EXSY experiments). Only the mode A was observed when naphthalimide was either non-substituted (1) or substituted by $\mathrm{Br}$ (2). With one or two electrodonating substituents $\left(\mathrm{OCH}_{3}(3)\right.$ or $\left(\mathrm{OCH}_{3}\right)_{2}(4)$ or $\left.\mathrm{N}\left(\mathrm{CH}_{3}\right)_{2}(5)\right)$ both modes $\mathrm{A}$ and B occured in a 50/50 ratio. This ratio depended on temperature for tweezer 3.

Keywords

tweezer; self-association; supramolecular recognition, ${ }^{1} \mathrm{H}$ NMR 


\section{Introduction}

Molecular tweezers (or clefts or clips) are preorganized synthetic receptors or hosts that have received increasing attention for the study of molecular recognition. Since the pioneering work reported by Chen and Whitlock in 1978 [1] numerous syntheses of molecular tweezers have been described in the literature [2-7]. In most of the publications the charge transfers between the tweezer and various guests (electron-poor aromatics, amino-acids, ions....) were described and characterized. More recently the interactions of tweezers with proteins or nucleic acids were even reported [8-11]. Additional papers explored their selfassembly (or self-association or dimerization) using ${ }^{1} \mathrm{H}$ NMR spectroscopy and X-ray diffraction, often associated with computational studies [12-19].

In a previous study, we have described the synthesis of molecular tweezers bearing two different arms and their association with the 2,4,7-trinitrofluoren-9-one (TNF) guest [20]. Then, we decided to investigate the self-assembly of five related tweezers (1-5) (Fig1). As a first common feature these compounds were bearing a $R(+)$ usnic acid arm and as a second one various substituted 1,8-naphthalimide moities in order to evaluate the substituents influence on their self-assembly. Tweezers 6 and 7 [21, 22] (Fig1) were included as references. Our study was essentially performed by ${ }^{1} \mathrm{H}^{\mathrm{NMR}}$ in $\mathrm{CD}_{2} \mathrm{Cl}_{2}$. Then the association could have been follow through the anisotropic effect variations on the aromatic protons. Some previous results of X-ray diffraction [20-22] allowed discussion.

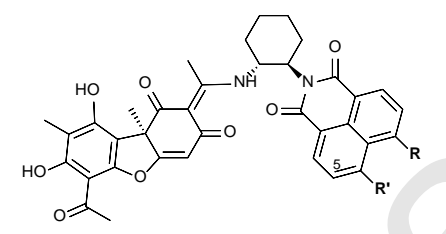

$\mathrm{R}=\mathrm{R}^{\prime}=\mathrm{H}$

$\mathrm{R}=\mathrm{H} \mathrm{R}^{\prime}=\mathrm{Br} 2$

$\mathrm{R}=\mathrm{H} \mathrm{R} \mathrm{R}^{\prime}=\mathrm{OCH}_{3} 3$

$\mathrm{R}=\mathrm{H} \mathrm{R}^{\prime}=\mathrm{N}\left(\mathrm{CH}_{3} \mathbf{H}^{2}\right.$

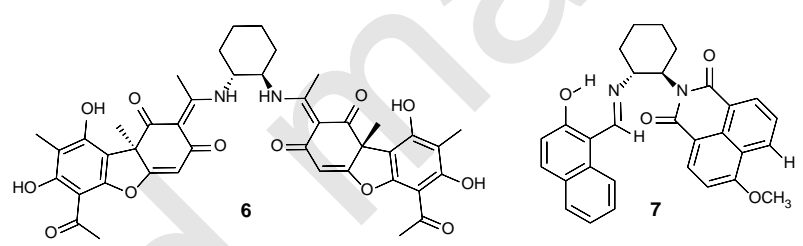

Fig1 Structure of the molecular tweezers 1-7

During the self-assembly process, two symmetric modes could occur: either the usnic acid moieties or the naphthalimide arms were face to face at the center of the dimeric structure, as illustrated by the mode $\mathbf{A}$ and the mode $\mathbf{B}$, respectively. The characteristics of the self-assembly modes $\mathbf{A}$ and $\mathbf{B}$ will be first described with $\mathbf{1}$ and the reference compounds $\mathbf{6}$ and $\mathbf{7}$. Then, the behavior of the four tweezers 2-5 will be reported. The weight of each self-assembly species depended on the nature of the substituents $\mathbf{R}$ and $\mathbf{R}^{\prime}$. A third non-symmetric association mode (mode $\mathbf{C}$ ) was also worth considering, with both a naphthalimide and an usnic acid arms at the center of the dimer (Fig2).
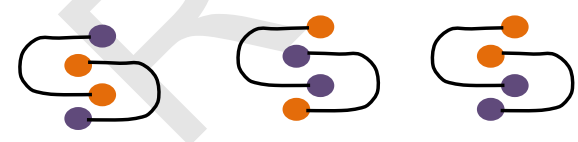

OUsnic acid

ONaphthalimide

\section{Mode A Mode B Mode C}

Fig2 Different self-assembly association modes 


\section{Results and discussion}

The ${ }^{1} \mathrm{H}$ NMR signals of $\mathrm{H}-5$ and $\mathrm{CH}_{3}$ signal of the groups $\mathrm{R}$ and $\mathrm{R}$ ' on the naphthalimide arm as well as the OH- $\beta$ signal on the usnic arm (Fig3) were selected. Indeed, these three signals, unambiguously attributed and well isolated on the spectra, were corresponding to protons included in the maximum interference area (Fig4). Their shift variations, observed when the tweezers concentration increased allowed the self-assembly study. After preliminary experiments performed to check spectra resolution and shift variation amplitude, the $258 \mathrm{~K}$ temperature has been chosen (whole spectra are given in Electronic Supplementary Material - ESM).

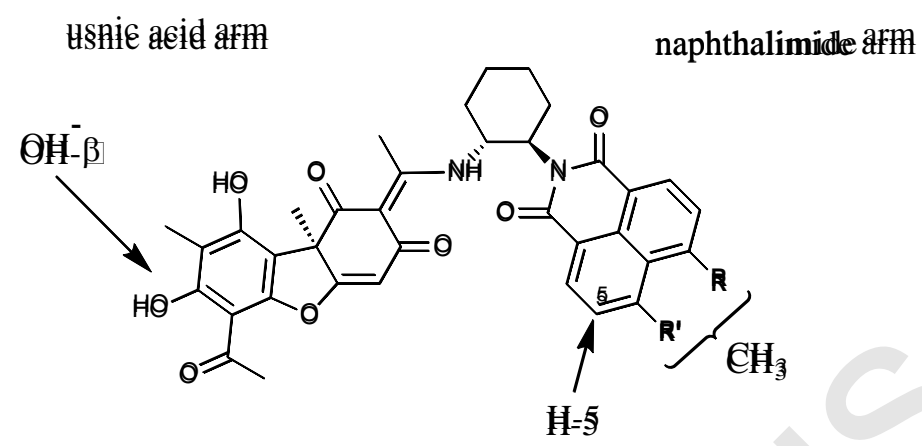

Fig3 Selected ${ }^{1} \mathrm{H}$ NMR signals

Description of the self-assembly modes A and B

As illustrated on X-ray diffraction (Fig4), tweezer $\mathbf{1}$ was auto-associated through the mode $\mathbf{A}$ where the usnic acid units are face to face, like the compound $\mathbf{6}[21,22]$. The ${ }^{1} \mathrm{H}$ NMR data of the aromatic proton $\mathrm{H}-5$ on the naphthalimide underwent low chemical shift variation $\Delta \delta=0.04 \mathrm{ppm}$ when increasing the concentration from $1.3 \mathrm{mM}$ to $80.0 \mathrm{mM}$ at $258 \mathrm{~K}$, attesting the weak effect of the usnic acid arm on the external naphthalimide one. The reciprocal effect on OH- $\beta$ was weaker for $\mathbf{1}$ than for $6(\Delta \delta=0.05 \mathrm{ppm}$ versus $\Delta \delta=0.21 \mathrm{ppm})$.
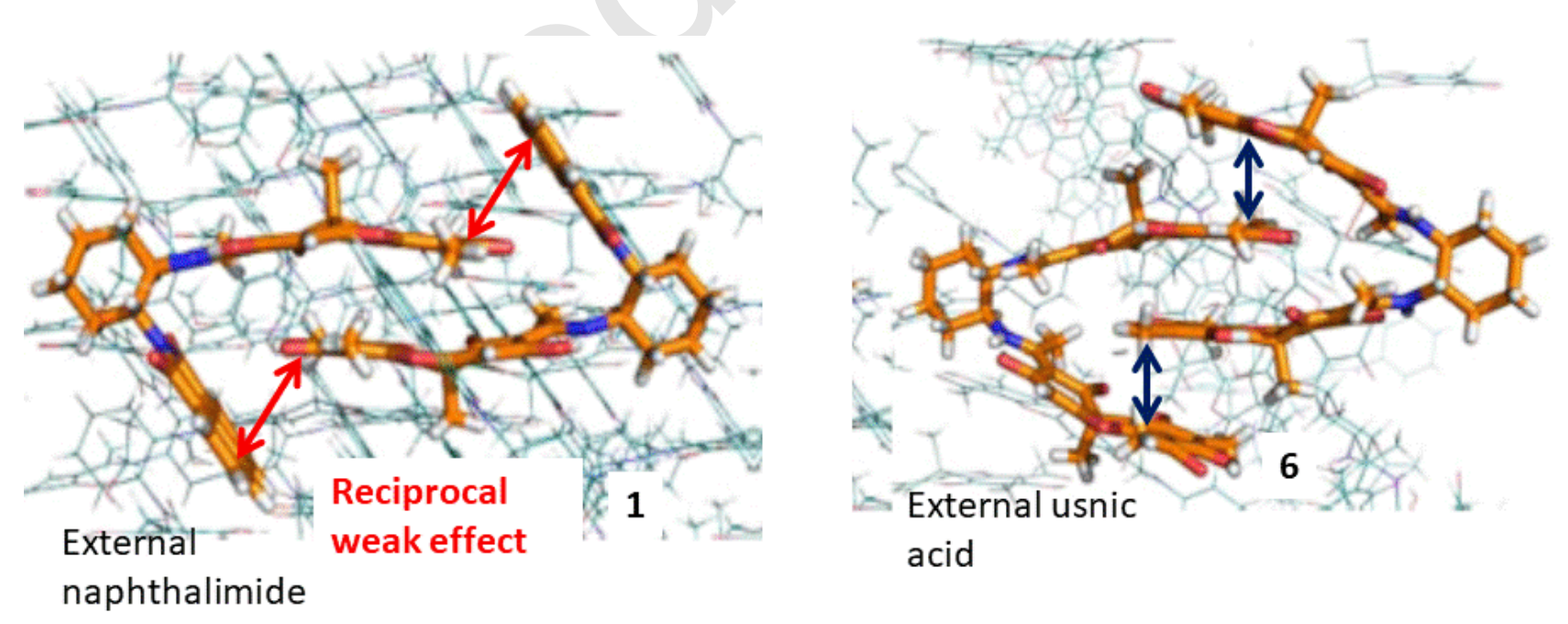

Fig4 X-ray structures of 1 and 6 . Arms reciprocal effects. 
Mode B could be evidenced by tweezer 7. We had previously observed [23] that no charge transfer with TNF occurred with one naphthalene arm derived of the 2-hydroxynaphthaldehyde (see Supplementary Material), suggesting that if a chemical shift variation was observed for the current tweezer $\mathbf{7}$, this meant that the naphthalimide moieties interacted with themselves within a mode B. Contrary to mode A, the methoxynaphthalimide arm protons ( $\mathrm{H}-5$ and H-7) were significantly shielded, exhibiting shift values of 0.22 and 0.25 ppm respectively (Fig5). It could be noted that the naphthalene arm (H-4' and N=CH) remained unaffected according to the shielding value of $\mathrm{N}=\mathrm{CH}$ and $\mathrm{H}-4$ ' of $0.03 \mathrm{ppm}$. Moreover, one can observe two sets of signals corresponding to $\alpha$ and $\beta$ conformers (Fig6) at low temperatures. This phenomenon was induced by the non-symmetrical arms of 7 and has been widely previously discussed [20].

These results validated the selection of H-5 as self-assembly marker: its inclusion into the tweezer resulted in a large shielding (above $0.25 \mathrm{ppm}$ ) evidencing the mode $\mathbf{B}$ while an external position lead to a weaker shielding indicating the mode $\mathbf{A}$, as already observed with naphthalene derivatives by Klärner [24] in $\mathrm{D}_{2} \mathrm{O}$. We will focus mainly on this proton for the further study of compounds 2-5.

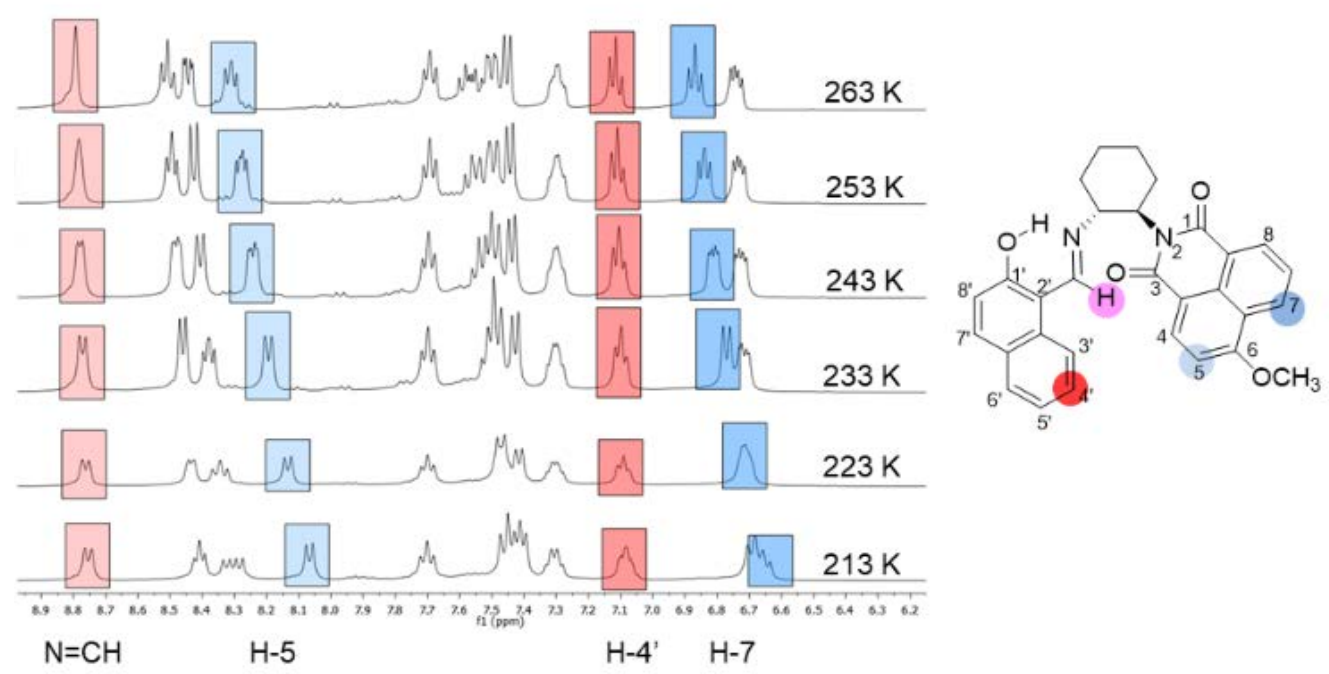

Fig5 Partial ${ }^{1} \mathrm{H}$ NMR spectra of 7 depending on temperature

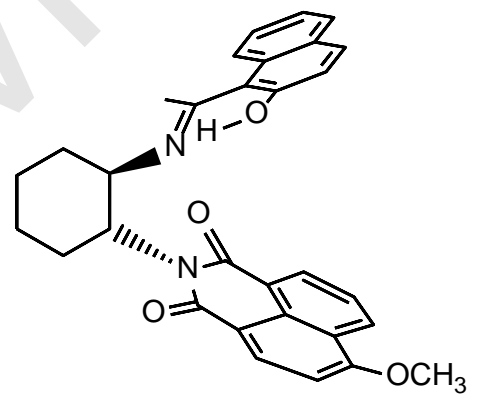

$7 \alpha$

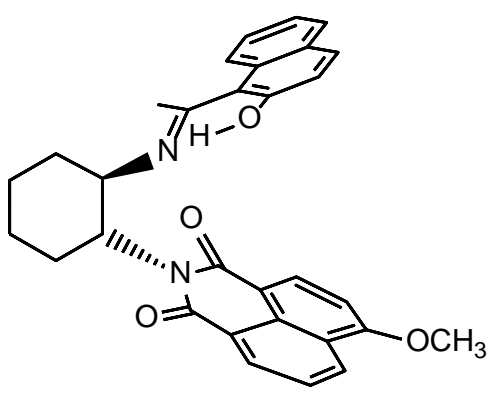

$7 \beta$

Fig6 Structures of $7 \boldsymbol{\alpha}$ and $7 \boldsymbol{\beta}$ conformers 
Stereoelectronic effects: tweezers 2-5

Withdrawing substituted arm tweezer 2

In the concentration range encompassing 1.1 to $69.4 \mathrm{mM}$ at $258 \mathrm{~K}$, tweezer 2 exhibited the same behaviour as compound 1 with a chemical shielding $\Delta \delta=0.12 \mathrm{ppm}$ for H-5 (see Supplementary Material). One can assume than self-assembly occured according to mode $\mathbf{A}$. A little stronger reciprocal effect on usnic $\operatorname{arm}\left(\Delta \delta_{\text {он- } \beta}=0.11 \mathrm{ppm}\right.$ versus $0.05 \mathrm{ppm}$ ) could be explained by the higher electronic density due to the Br substituent.

\section{Electrodonating substituted arms tweezers 3, 4 and 5}

At first, considering the partial ${ }^{1} \mathrm{H}$ NMR spectra of 3 at $258 \mathrm{~K}$ (Fig7), one can observe the splitting of the aromatic proton H-5. A triplet was observed at $7.02 \mathrm{ppm}$ at $1.1 \mathrm{mM}$ which split with different amplitude in two signals to reach $6.93 \mathrm{ppm}$ and 6.35 ppm at $72.6 \mathrm{mM}$, meaning shieldings of 0.09 and $0.67 \mathrm{ppm}$ respectively. The same observations can be done for the $\mathrm{OCH}_{3}$ signal. A singlet peak was still observed at $4.5 \mathrm{mM}(4.06 \mathrm{ppm})$ but split at $9.1 \mathrm{mM}$ to give 2 singlets which differently shift when concentration increases. At $72.6 \mathrm{mM}$, signals were recorded at $3.98 \mathrm{ppm}$ and $3.57 \mathrm{ppm}$ leading respectively to 0.08 and 0.49 ppm shieldings. Compounds $\mathbf{4}$ and $\mathbf{5}$ exhibited the same behaviors when studying at the different concentrations. These behaviors let us to conclude than self-assembly occured according to both modes $\mathbf{A}$ and $\mathbf{B}$ for tweezers 3-5.

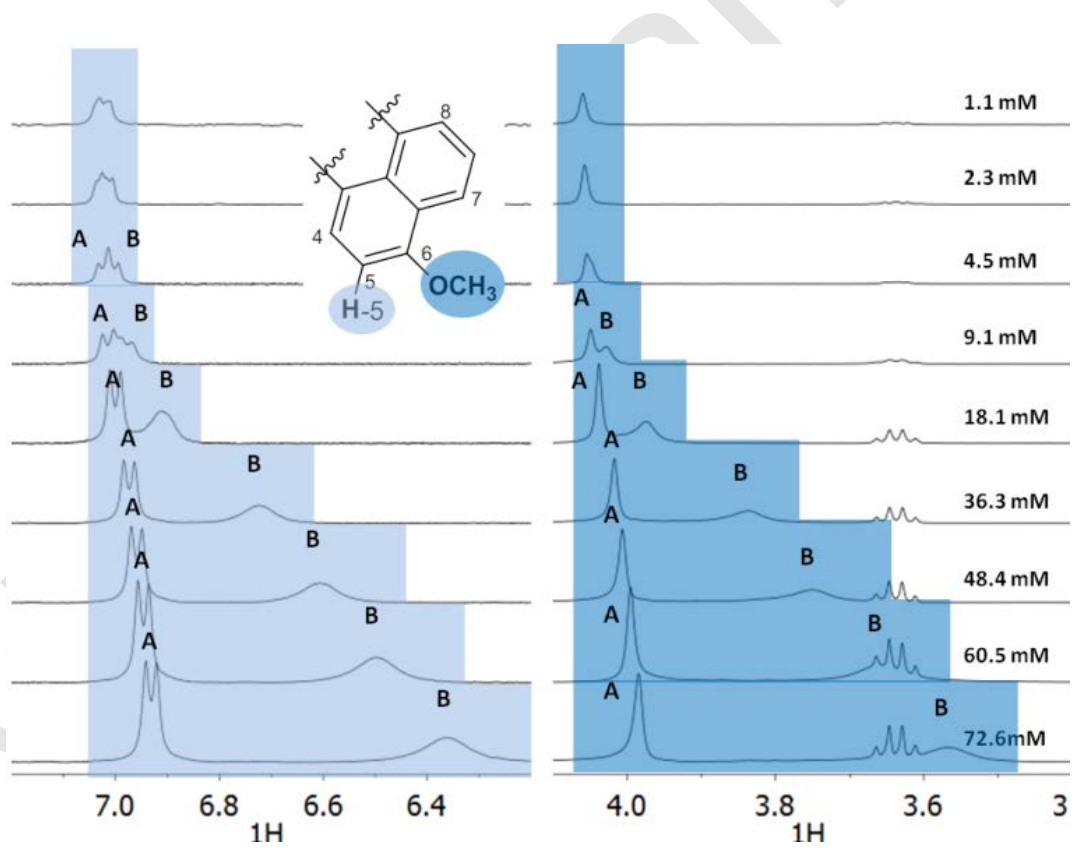

Fig7 Details of the ${ }^{1} \mathrm{H}$ NMR spectra of 3: signals of $\mathrm{OCH}_{3}$ and $\mathrm{H}-5$ at $258 \mathrm{~K}$

Concerning the splitting of the methoxy group signal, we could note that the singlets kept the same integration with a 50/50 ratio suggesting equal affinity constants $K_{\mathrm{A}}$ and $K_{\mathrm{B}}$ (Fig6). On the two new sets of signals (Fig7) a signal broadening was observed, consistent with a relatively fast exchange in the chemical shift timescale between the self-assembled and the free monomeric form. According to it, an apparent interconversion between both forms was observed on EXSY spectra that 
evidenced the high dissociation-association-rate constants for both self-assembly modes A and $\mathbf{B}$ (Fig8). $\mathbf{3}$ EXSY spectrum is presented Figure 9. The magnetization exchange rate constants $k^{\prime}{ }_{1}$ and $k_{-1}{ }_{-1}$ were $4.3 \pm 0.2 \mathrm{~s}^{-1}$ for compound $\mathbf{3}$ at $278 \mathrm{~K}$ and 72.5 $\mathrm{mM}$ in agreement with the low affinity constants values.
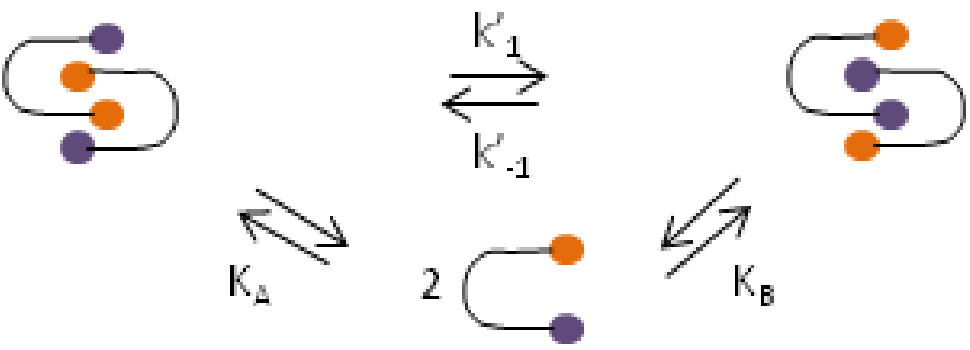

Fig8 Association-dissociation dynamics scheme

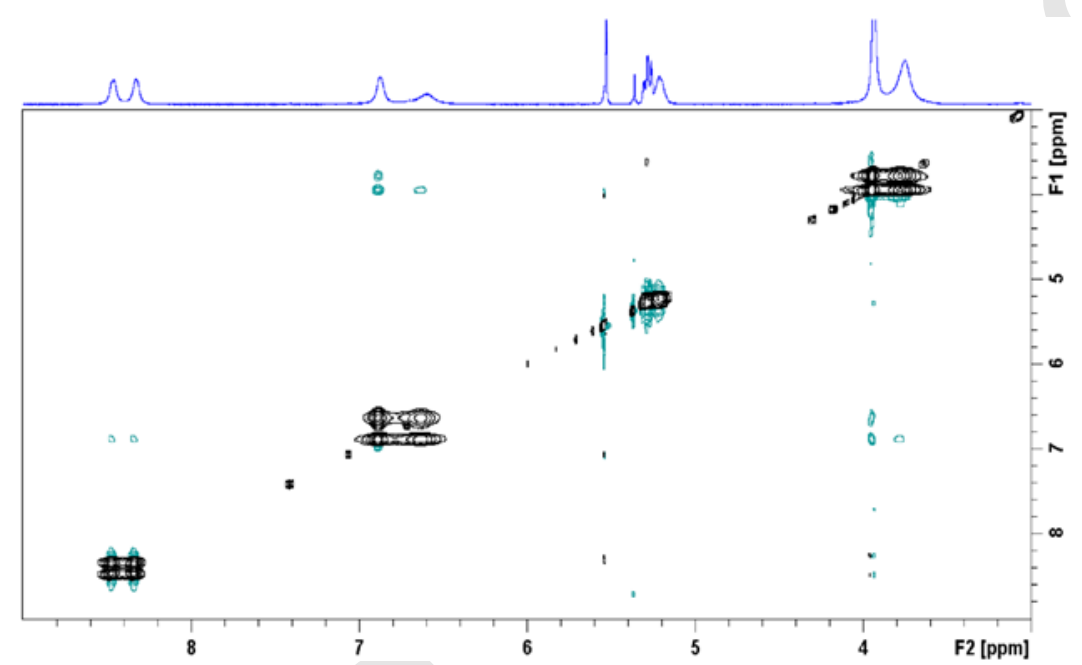

Fig9 EXSY spectrum of 3. Black cross peaks denote chemical exchange and blue ones denote NOEs.

On Figure 10, the shielding values of both ortho protons ( $\mathrm{H}-5)$ and $\mathrm{X}-\mathrm{CH}_{3}$ protons, measured in the concentration range 1-70 $\mathrm{mM}$ for tweezers 3-5, are presented for both self-assembly modes $\mathbf{A}$ and $\mathbf{B}$. Concerning the self-assembly mode $\mathbf{A}$, the reciprocal effect of the usnic arm on $\mathrm{H}-5$ and $\mathrm{CH}_{3}$ (R,R') remained low: $\Delta \delta<0.1 \mathrm{ppm}$ for 3 and 5 in good agreement with effects observed with 1 and 2 . The disubstituted tweezer $\mathbf{4}$ exhibited slightly higher values $\left(\Delta \delta_{\mathrm{H}-5}=0.25 \mathrm{ppm}, \Delta \delta_{\mathrm{OMe}}=0.15\right.$ ppm ) but still consistent with the mode $\mathbf{A}$.

In the self-assembly mode $\mathbf{B}$, chemical shift variations of the naphthalimide protons dramatically differed for $\mathbf{3}$ and $\mathbf{4}$. They reached $\Delta \delta_{\mathrm{H}-5} \approx 0.7$ and $\Delta \delta_{\mathrm{OMe}}=0.5 \mathrm{ppm}$ at about $70 \mathrm{mM}$ (only one signal was observed for both methoxy groups). The chemical shift variation was reduced for $\mathbf{5}$ ( $<0.10 \mathrm{ppm}$ for both signals). 


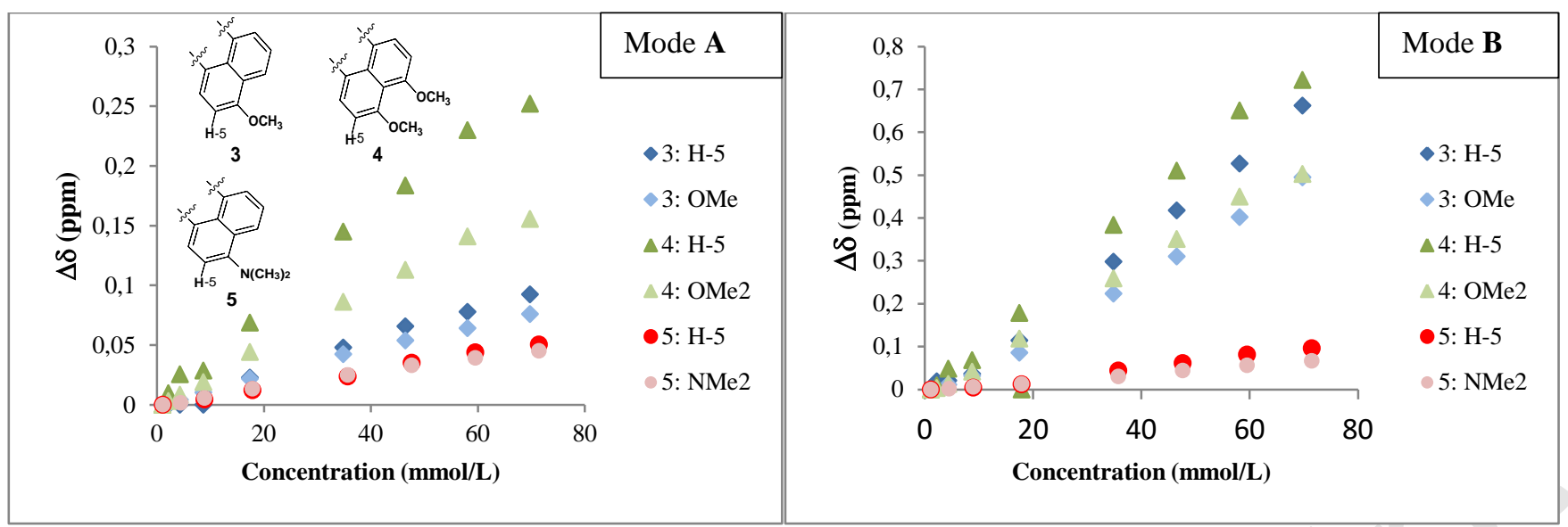

Fig10 Shielding of some protons of 3, 4 and 5 at $258 \mathrm{~K}$ according to mode A (left) and mode B (right) (numbering is given on the structures)

In the literature $[25,26]$ the importance of electrostatic interaction between static molecular charge distributions to explain non-covalent interaction and molecular recognition events has been highlighted. Thus, in table 1 calculated electronic potential values (see Supplementary Material) are reported. When core charge is negative $(\mathbf{1}, \mathbf{2})$, only mode A was observed whereas both modes $\mathbf{A}$ and $\mathbf{B}$ exist when it becomes positive (3-5). In mode $\mathbf{B}$, in addition of the electronic potential values, the observed chemical shift variation of $\mathbf{4}$ (table 1) was modulated by the steric hindrance between the two methoxy substituents. The weak shielding observed for 5 was related to an ineffective delocalization of the lone pair electrons of nitrogen owing to its pseudo equatorial position [27] and to the steric hindrance. In the case of $\mathbf{3}$ and $\mathbf{4}$, the high shielding of the $\mathrm{CH}_{3}$ groups ( $\Delta \delta$ close to $0.70 \mathrm{ppm}$ ) gave evidence of their position and of their closeness with the naphthalimide aromatic rings [28]. The resulting $\mathrm{CH} / \pi$ interactions were also in favor of a charge transfer between two naphthalimide arms [29].

Table 1 Electrodonating substituents impact on naphthalimide arm: calculated core charge and electrostatic potential. (Negative and positive potentials are respectively red and blue).

\begin{tabular}{lccccc}
\hline & $\mathbf{1}$ & $\mathbf{2}$ & $\mathbf{3}$ & $\mathbf{4}$ & $\mathbf{5}$ \\
\hline $\begin{array}{l}\text { Core } \\
\text { charge }\end{array}$ & -0.22 & -0.12 & 0.08 & 0.31 & 0.03 \\
\hline
\end{tabular}

\section{Existence of mode C?}

Mode $\mathbf{C}$ was characterised by an acid usnic and a naphthalimide moiety in the center of the tweezer (Fig2). Such an interaction should lead to four non-equivalent magnetical moieties. ${ }^{1} \mathrm{H}$ NMR spectra in accordance with hypothesis were never observed meaning that the lifetime of such species was not large enough to permit detection. 


\section{Temperature influence on self-association}

In order to better understand the self-assembly process, the temperature influence on the mode $\mathbf{A} /$ mode $\mathbf{B}$ ratio was explored using a concentrated solution (about $70 \mathrm{mM}$ ) for $\mathbf{3}$ and $\mathbf{4}$ which presented the highest shielding values. If the ratio remained constant at 50/50 for 4, it reached 35/65 for 3 at $238 \mathrm{~K}$. As expected, a temperature decreasing induced a $\Delta \delta$ increasing for both tweezers.

In the Figure 11 were reported the shielding variations $\Delta \delta\left(\Delta \delta=\delta_{\mathrm{T}}-\delta_{298}\right)$ of the $\mathrm{OCH}_{3}$ signals (at $\left.400 \mathrm{MHz}\right)$ for the two modes (See spectra in Supplementary Material). We could note that in the mode $\mathbf{B}$ at $238 \mathrm{~K}$, the shielding effect was nearly twice as high for 4 than for $\mathbf{3}$ ( $\Delta \delta=1.10 \mathrm{ppm}$ and $0.58 \mathrm{ppm}$, respectively).

As previously described for $\mathbf{2}$ and 7, two favored conformers $\alpha$ and $\beta$ existed due to the non-symmetry of either usnic acid (2) or naphthalene (7). The equilibrium rate decreased when temperature decreased leading to two distinguishable populations $\alpha$ and $\beta$ at $238 \mathrm{~K}$. The $\alpha \alpha, \beta \beta$ and $\alpha \beta$ associations were identical for $\mathbf{4}$ but they clearly differed for $\mathbf{3}$ for which anti associations $(\alpha \beta)$ were favored over the syn ones ( $\alpha \alpha$ or $\beta \beta$ ) in which the two methoxy interfere (Fig12). This behavior could explain the ratio between modes $\mathbf{A}$ and $\mathbf{B}$ which reached 35:65 at $238 \mathrm{~K}$ while it is 50:50 at higher temperatures.

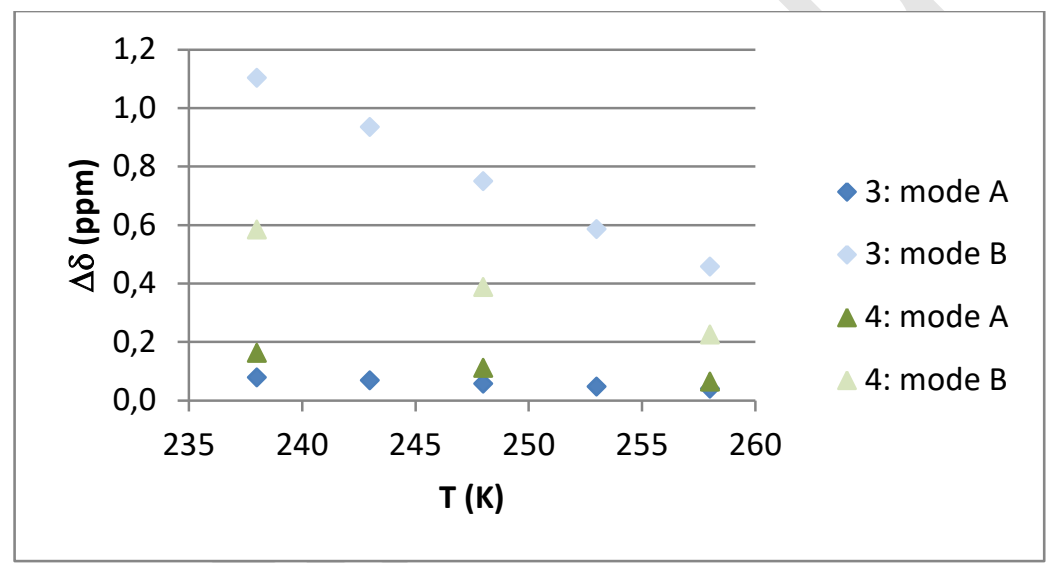

Fig11 $\Delta \delta\left(\delta_{\mathrm{T}}-\delta_{298}\right)$ in ppm for $\mathrm{OCH}_{3}$ signal vs temperature in $\mathrm{K}$ for modes $\mathbf{A}$ and $\mathbf{B}$ for compounds $\mathbf{3}$ and $\mathbf{4}$

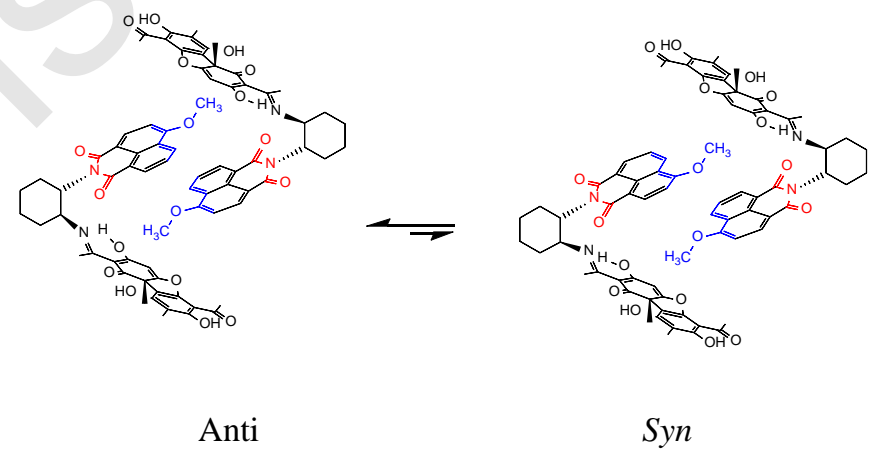

Fig12 Syn and anti associations of 3

\section{Conclusion}


This second contribution devoted to the design and the synthesis of tweezers possessing two different arms confirms the interest of such non-symmetrical molecules for studying molecular recognition phenomena. The self-association can occurred according to two different modes. The substituents stereoelectronical effects on the charge transfer and then on the selfassociation modes was highlighted like in the previous paper concerning the tweezer interaction with the TNF [20]. Thus, little modifications can induce a strong change in the recognition. Such observations are extremely frequent in medicinal chemistry [30, 31]. The design and the study of non-symmetrical tweezers with moderate affinity constant $K$ could be helpful for the drug design but also for mechanistic propositions in chemistry [32].

\section{Experimental Section}

Materials and methods

All reagents of high quality were purchased from commercial suppliers and used without further purification. ${ }^{1} \mathrm{H}$ and ${ }^{13} \mathrm{C}$ NMR spectroscopic data were recorded on Bruker apparatus at either 300, 400 or $500 \mathrm{MHz}$ and either 75, 100 or $125 \mathrm{MHz}$, respectively. ${ }^{1} \mathrm{H}$ NMR titration experiments were performed at $500 \mathrm{MHz}$. The undeuterated residue of the solvent was used as internal standard. The $\delta$ values are given in ppm and the coupling constants in Hz. The multiplicity of the signals is reported as $\mathrm{s}$ (singlet), d (doublet), t(triplet), q (quadruplet) and $\mathrm{m}$ (multiplet). As previously reported, ${ }^{13} \mathrm{C}$ signals could be either coalescent (signals are indicated by the symbol *) or split in two signals. HRMS analyses are obtained using an Orbitrap instrument for ESI. Melting points are uncorrected. Thin layer chromatography was performed using precoated Merck silica gel plate 60 F254 (0.2 mm thickness) and the Rf values are given for the eluent used during purification. Column chromatography was done using silica gel 0.063-0.2 $\mathrm{mm}$. The chromatography solvents were eliminated from the tweezers by using vacuum pomp $\left(10^{-2} \mathrm{~mm} \mathrm{Hg}\right)$ and heating $\left(\mathrm{CH}_{2} \mathrm{Cl}_{2}, \mathrm{CH}_{3} \mathrm{CO}_{2} \mathrm{Et}, \mathrm{C}_{2} \mathrm{H}_{5} \mathrm{OH}\right)$ but traces are present in some spectra.

The ${ }^{1} \mathrm{H}$ NMR self-assembly studies were performed at $400 \mathrm{MHz}$ using $\mathrm{CD}_{2} \mathrm{Cl}_{2}$ as solvent and all spectra are given in SM. The ${ }^{1} \mathrm{H}$ NMR spectra were recorded on a Bruker AVANCE III $400 \mathrm{MHz}$ Ultrashield Plus spectrometer operating at $400.13 \mathrm{MHz}$ for ${ }^{1} \mathrm{H}$ observation. A $5 \mathrm{~mm}$ Bruker PABBO BB-1H/D Z-GRD probehead was used for the ${ }^{1} \mathrm{H}$ analysis. NMR experiments were acquired using zg30 Bruker sequences supplied in TopSpin 2.1, processed and analyzed in MestReNova 10.0.0 (Mestrelab Research S.L). The temperature of each experiment was controlled by a VTU Unit with a thermocouple. T. For the $1 \mathrm{D}{ }^{1} \mathrm{H}$ NMR spectra, a 1 second relaxation delay and a 5.452 seconds acquisition time were used.

Electrostatic potential has been calculated with Jaguar, as implemented in Maestro v.11.5 (Schrödinger). The surface potential was determined after geometry optimization of each molecule using B3LYP functional and 6-31G** basis set (SCF convergence criterion of $\left.5.10^{-5} \mathrm{Ha}\right)$.

EXSY NMR spectra were recorded at $278 \mathrm{~K}$ on a Bruker Avance 500 spectrometer equipped with a BBO probe using 5 mm sample tubes and deuterated dichloromethane as solvent. The spectra were recorded in the phase-sensitive mode using standard Bruker sequences and 8 transients for each $t 1$ value. Spectral windows were of $5000 \mathrm{~Hz}$ in both dimensions with $4 \mathrm{k} x 256$ data points, mixing times $\tau \mathrm{m}$ of $3 \mu \mathrm{s}$ and $0.5 \mathrm{~s}$ were used, while keeping a constant repetition time of $1.9 \mathrm{~s}$. Before the Fourier transformation, the data were processed with a sine-bell function in both $F 1$ and $F 2$ domains, and zero filling was applied to obtain a $2 \mathrm{k}$ x1k transformed matrix. Peak volumes were integrated using Bruker NMR software TOPSPIN.

The calculations of the exchange rates were performed using the EXSYCalc software [33]. 
Synthetic procedures

Synthesis of 9

1,8-Dimethoxynaphthenedione can occur according to S.Lahore [34]

4,6-Dimethoxy-1,8-naphthalimide 9 [35] $285 \mathrm{mg}$ (1.18 mmol) of 1,8-Dimethoxynaphthenedione and $1.07 \mathrm{~g}$ of oxone (7.06 mmol; 6 eq) were suspended in $20 \mathrm{~mL}$ of methanol and refluxed for $96 \mathrm{~h}$. After cooling the mixture was poured into water and the obtained solid was washed using methanol and dried under vacuum. $310 \mathrm{mg}$ of a very insoluble solid was obtained and

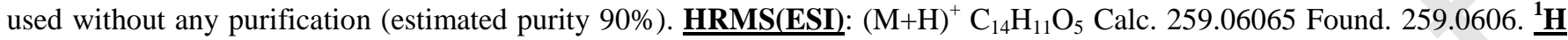
NMR $\left(\mathrm{CDCl}_{3}, 300 \mathrm{MHz}, 298 \mathrm{~K}\right): 8.64$ (d, 2H), 7.15 (d,2H), 4.15 (s, 6H).

Synthesis of 11 [21]

$270 \mathrm{mg}$ of 9 (1.05 mmol) and $360 \mathrm{mg}$ of 1,2-diaminocyclohexane 8 (3 eq) in $15 \mathrm{~mL}$ of ethanol were refluxed for $48 \mathrm{~h}$. The solvent was evaporated under vacuum and $\mathbf{1 1}$ was purified by chromatography on silica gel using $\mathrm{CH}_{2} \mathrm{Cl}_{2}: \mathrm{MeOH}^{90: 10}$ as eluent (blue fluorescence). Only $100 \mathrm{mg}$ (Yield 29\%) of a yellow-brown solid were obtained probably because of the very bad solubility of 9. $\underline{\mathbf{R f}} 0.56 \underline{\mathbf{F}^{\circ} \mathbf{C}}$ : 244-246; $\underline{\mathbf{H R M S}(\mathbf{E S I})}:(\mathrm{M}+\mathrm{H})^{+} \mathrm{C}_{20} \mathrm{H}_{23} \mathrm{~N}_{2} \mathrm{O}_{4}$ calc.: 355.16578 found.: $355.1659 .{ }^{1} \mathbf{H}$ NMR ( $\left.\mathrm{CDCl}_{3}, 300 \mathrm{MHz}, 298 \mathrm{~K}\right): 8.53$ (d 2H), 7.00 (d, J=9Hz, 2H), 4.75 (td, J=3.7 and 11Hz, 1H), 3.78 ((td, J=3.7 and 11Hz, 1H), 4.07 (s, 6H), 2.51 (qd, J=3.7 and 12Hz, 1H), 2.08 (dm, J=11Hz, 1H), 1.70-1.85 (m, 3H), 1.45 (m,2H), 1.25 (m, 1H) NH $\mathrm{N}_{2}$ not attributed. ${ }^{13} \mathrm{C}$ NMR $\left(\mathrm{CD}_{2} \mathrm{Cl}_{2}, 75.4 \mathrm{MHz}, 298 \mathrm{~K}\right): 165.6,164.5,162.9,134.5,133.7,132.3,115.5,114.8,106.3,60.8,56.4$, 50.4, 37.0, 28.6, 26.2, 25.5 .

\section{Synthesis of tweezers 4 and 7 (Scheme 1)}

The synthesis strategy, previously reported for tweezers $\mathbf{1}, \mathbf{2}, \mathbf{3}$ and $\mathbf{5}$ [20-22], was employed to prepare $\mathbf{4}$ and $\mathbf{7}$ (scheme 1) from the $R R\left(^{+}\right)$diaminocyclohexane $\mathbf{8}$. The naphthalimides were introduced in the first step and then the (+)-usnic acid and the 2-hydroxynaphthaldehyde led us to obtain the tweezers 4 and 7 respectively.

To $175 \mathrm{mg}$ of 10 (0.54 mmol) in $10 \mathrm{~mL}$ of $\mathrm{C}_{2} \mathrm{H}_{5} \mathrm{OH}$ were added $93 \mathrm{mg}$ of 2-hydroxynaphthaldhyde ( $\left.0.54 \mathrm{mmol}\right)$. After $48 \mathrm{~h}$ of refluxing, the solvent is removed under vacuum and 7 was purified by chromatography on silica gel using $\mathrm{CH}_{2} \mathrm{Cl}_{2} / \mathrm{CH}_{3} \mathrm{OH}$ 99/1 as eluent. $76 \mathrm{mg}$ of 7 were obtained as a brown oil giving a solid after 2 weeks. Yield: 16\% (not optimized). Rf: 0.4 .

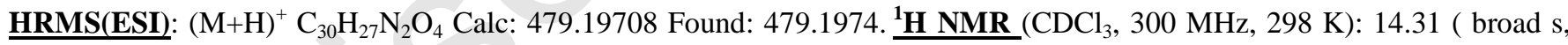
1H), 8.74 (s, 1H), 8.55 (dd, J=1.2 Hz and J=7.3 Hz, 1H), 8.50 (d, J=8.3 Hz, 1H), 8.43 (d, J=8.3 Hz, 1H), 7.62 (m, 2H), 7.50 (d, J=9.3 Hz, 1H), 7.45 (dd, J=1.2 Hz and J=8.0 Hz, 1H), $7.26(\mathrm{~m}, 1 \mathrm{H}), 7.10(\mathrm{~m}, 1 \mathrm{H}), 6.94$ (d, J=8.2 Hz, 1H), 6.78 (d, J=9.2 Hz, 1H), 5.32 (m, 1H), 4.72 (td, J=3.9 Hz and J=10.8 Hz, 1H), 4.05 (s, 3H), 2.60 (m, 1H), 2.19 (d, 1H), 1.48-2.03 (m, 6H) + water;. ${ }^{13} \mathrm{C}$ NMR $\left(\mathrm{CDCl}_{3}, 75.4 \mathrm{MHz}, 298 \mathrm{~K}\right): 174.3,165.4,164.9,164.4,164.1,160.9,157.3,136.4,133.6,129.6,129.0$, $128.8,127.7,126.2,126.0,124.3,123.4,122.5,118.1,106.9,105.3,63.0,57.2,56.2,35.2,28.5,25.8,24.9$.

Synthesis of 4 [21]

$100 \mathrm{mg}$ of $\mathbf{1 1}(0.28 \mathrm{mmol})$ and $95 \mathrm{mg}$ of usnic acid (1 eq) in $7 \mathrm{~mL}$ of ethanol were refluxed for $4 \mathrm{~h}$. The solvent was evaporated under vacuum and 4 was purified by chromatography on silica gel using $\mathrm{CH}_{2} \mathrm{Cl}_{2}: \mathrm{MeOH}$ 99:1 as eluent (blue fluorescence). 170

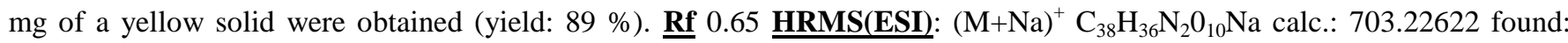
703.226. ${ }^{1} \mathrm{H} \mathrm{NMR}\left(\mathrm{CDCl}_{3}, 300 \mathrm{MHz}, 298 \mathrm{~K}\right): 13.30(\mathrm{~s}, 2 \mathrm{H}), 11.82\left(\mathrm{~s}^{*}, 1 \mathrm{H}\right), 8.57\left(\mathrm{~s}^{*}, 1 \mathrm{H}\right), 8.48\left(\mathrm{~s}^{*}, 1 \mathrm{H}\right), 6.99(\mathrm{~d}, \mathrm{~J}=8.7 \mathrm{~Hz}, 2 \mathrm{H})$, $5.60(\mathrm{~s}, 1 \mathrm{H}), 5.24(\mathrm{td}, \mathrm{J}=3.6$ and $11.0 \mathrm{~Hz}, 1 \mathrm{H}), 5.11(\mathrm{qd}, \mathrm{J}=3.6$ and $10.0 \mathrm{~Hz}, 1 \mathrm{H}), 4.04(\mathrm{~s}, 6 \mathrm{H}), 2.59(\mathrm{~s}, 3 \mathrm{H}), 2.58(\mathrm{~m}, 1 \mathrm{H}), 2,53(\mathrm{~s}$, 
3H), $2.17(\mathrm{~m}, 1 \mathrm{H}), 2.03(\mathrm{~s}, 3 \mathrm{H}), 1.92(\mathrm{~m}, 3 \mathrm{H}), 1.50-1.80(\mathrm{~m}, 3 \mathrm{H}), 1.44(\mathrm{~s}, 3 \mathrm{H}) .{ }^{13} \mathrm{C} \mathrm{NMR}\left(\mathrm{CDCl}_{3}, 75.4 \mathrm{MHz}, 298 \mathrm{~K}\right): 200.8,198.1$, $174.5,173.6,164.9 *, 163.5,163.4,158.4,156.0,135.3,134.1,132.5,114.3,107.9,106.6,105.2,102.7,102.1,101.3,56.8$,

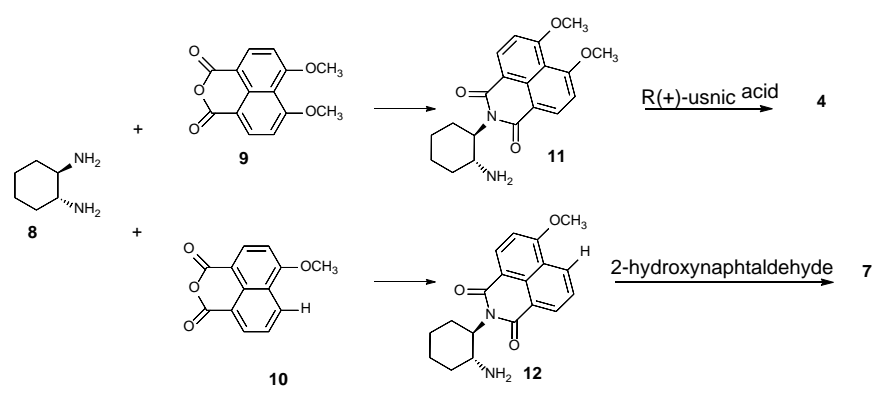

Scheme 1 Synthesis strategy to prepare compounds $\mathbf{4}$ and 7

\section{Acknowledgements}

The authors Pr D. Jacquemin and Dr J. Graton (CEISAM, Nantes, France) for fruitful discussions, Dr P. Jéhan (SCANMAT, Rennes, France) for mass spectrometry and Dr N. Levoin (Bioprojet-Biotech, France) for charge calculations. We are most grateful to the PRISM core facility (Rennes-Angers, France) for NMR spectrometer access.

\section{References}

1. Chen, C.-W., Whitlock, H.W.J.: Molecular Tweezers: A Simple Model of Bifunctional Intercalation. J. Am. Chem. Soc. 100, 4921-4922 (1978)

2. Hardouin-Lerouge, M., Hudhomme, P., Sallé, M.: Molecular clips and tweezers hosting neutral guests. Chem. Soc. Rev. 40, 30-43 (2011)

3. Leblond, J., Petitjean, A.: Molecular tweezers: Concepts and Applications. ChemPhysChem. 12, 1043-1051 (2011)

4. Klärner, F., Kahlert, B.: Molecular Tweezers and Clips as Synthetic Receptors . Molecular Recognition and Dynamics in Receptor - Substrate Complexes. Acc. Chem. Res. 36, 919-932 (2003).

5. He, Z., Yang, X., Jiang, W.: Synthesis, Solid-State Structures, and Molecular Recognition of Chiral Molecular Tweezer and Related Structures Based on a Rigid Bis-Naphthalene Cleft. Org. Lett. 17, 3880-3883 (2015).

6. Düker, M.H., Schäfer, H., Zeller, M., Azov, V.A.: Rationally Designed Calix[4]arene - Pyrrolotetrathiafulvalene Receptors for Electron-Deficient Neutral Guests. J. Org. Chem. 78, 4905-4912 (2013).

7. Harmata, M.: Chiral molecular tweezers. Acc. Chem. Res. 37, 862-873 (2004)

8. Herzog, Ga., Shmueli, M.D., Levy, L., Engle, L., Gazit, E., Klarner, F.-G., Schrader, T., Bitan, G., Segal, D.: The LysSpecific Molecular Tweezer, CLR01, Modulates Aggregation of the Mutant p53 DNA Binding Domain and Inhibits Its Toxicity. Biochemistry. 54, 3729-3738 (2015).

9. Zimmerman, S.C.: A journey in bioinspired supramolecular chemistry : from molecular tweezers to small molecules that target myotonic dystrophy. Beilstein J. Org. Chem. 12, 125-138 (2016).

10. Bier, D., Mittal, S., Bravo-rodriguez, K., Sowislok, A., Guillory, X., Briels, J., Heid, C., Bartel, M., Wettig, B., Brunsveld, L., Sanchez-garcia, E., Schrader, T., Ottmann, C.: The Molecular Tweezer CLR01 Stabilizes a Disordered Protein-Protein Interface. J. Am. Chem. Soc. 139, 16256-16263 (2017).

11. Vöpel, T., Bravo-rodriguez, K., Mittal, S., Vachharajani, S., Gnutt, D., Sharma, A., Steinhof, A., Fatoba, O., Ellrichmann, G., Nshanian, M., Heid, C., Loo, J.A., Klarner, F., Schrader, T., Bitan, G., Wanker, E.E., Ebbinghaus, S., Sanchez-garcia, E.: Inhibition of Huntingtin Exon - 1 Aggregation by the Molecular Tweezer CLR01. J. Am. Chem. Soc. 139, 5640-5643 (2017).

12. Valdes, C., Urs, P., Toledo, L.M., Kubik, S.W., Rebek, J.: Synthesis and Self-Assembly of Pseudo-Spherical Homo- and Heterodimeric Capsules. J. Am. Chem. Soc. 117, 12733-12745 (1995)

13. Haino, T., Fujii, T., Fukazawa, Y.: Guest Binding and New Self-Assembly of Bisporphyrins. J. Org. Chem. 71, 25722580 (2006) 
14. Haino, T., Fujii, T., Watanabe, A., Takayanagi, U.: Supramolecular polymer formed by reversible self-assembly of tetrakisporphyrin. PNAS. 106, 1-3 (2009)

15. Branchi, B., Ceroni, P., Balzani, V., Cartagena, M.C., Klarner, F.-G., Schrader, T., Vogtle, F.: Fluorescent water-soluble molecular clips. Self-association and formation of adducts in aqueous and methanol solutions. New J. Chem. 33, 397407 (2009).

16. Chou, T.-C., Li, Y.-J.: Synthesis and molecular assembly of benzenoid ring-mounted U-shaped septuple-bridged [7,7]orthocyclophanes walled by cofacial quinoxaline rings. Tetrahedron. 71, 5620-5633 (2015).

17. Kim, S.K., Lim, J.M., Pradhan, T., Jung, H.S., Lynch, V.M., Kim, J.S., Kim, D., Sessler, J.L.: Self-association and nitroaromatic-induced deaggregation of pyrene substituted pyridine amides. J. Am. Chem. Soc. 136, 495-505 (2014).

18. Colquhoun, H.M., Zhu, Z., Cardin, C.J., Gan, Y., Drew, M.G.B.: Sterically controlled recognition of macromolecular sequence information by molecular tweezers. J. Am. Chem. Soc. 129, 16163-74 (2007).

19. Bosquez, M., Cambray, A., Miralrio, A., Castillo, R., Salcedo, R.: Weak bonds between molecular tweezers and their guests. Comput. Theor. Chem. 1115, 335-343 (2017).

20. Jaunet-Lahary, T., Jacquemin, D., Legouin, B., Questel, J.-Y. Le, Cupif, J.-F., Toupet, L., Uriac, P., Graton, J.: Dissymmetric Molecular Tweezers in Host-Guest Complexes: Internal or External Complexation? J. Phys. Chem. C. 119, 3771-3779 (2015).

21. Legouin, B., Uriac, P., Tomasi, S., Toupet, L., Bondon, A., van de Weghe, P.: Novel Chiral Molecular Tweezer from. Org. Lett. 11, 745-748 (2009)

22. Graton, J., Legouin, B., Besseau, F., Uriac, P., Questel, J. Le, Weghe, P. Van De, Jacquemin, D.: Molecular Tweezers in Host - Guest Complexes : A Computational Study through a DFT - D Approach. J. Phys. Chem. C. 116, 23067-23074 (2012)

23. Legouin, B., Gayral, M., Uriac, P., Cupif, J.F., Levoin, N., Toupet, L., Van De Weghe, P.: Molecular tweezers: Synthesis and formation of host-guest complexes. Eur. J. Org. Chem. 5503-5508 (2010).

24. Klarner, F.-G., Nellesen, A., Zienau, J., Ochsenfeld, C., Schrader, T.: Molecular Tweezer and Clip in Aqueous Solution : Unexpected Self-Assembly , Powerful Host - Guest Complex Formation, Quantum Chemical ${ }^{1} \mathrm{H}$ NMR Shift Calculation. J. Am. Chem. Soc. 128, 4831-4841 (2006)

25. Hunter, C.A.: The role of aromatic interactions in molecular recognition. Chem. Soc. Rev. 23, 101 (1994).

26. Kamieth, M., Klärner, F.-G., Diederich, F.: Modeling the Supramolecular Properties of Aliphatic-Aromatic Hydrocarbons with Convex-Concave Topology. Angew. Chem. Int. Ed. 37, 3303-3306 (1998)

27. Corbel, J.-C; Uriac, P., Huet, J., Martin, C.A.E.; Advenier, A. 1-Benzazepine derivatives acting as ATP-dependent potassium-channels antagonists. Eur. J; Med. Chem. 30, 3-13 (1995)

28. Tobe, Y., Naemura, K.: A new entry to [6](1,4)naphthalenophane and [6](1,4)anthracenophane: synthesis of perisubstituted derivatives. Tetrahedron Lett. 36, 939-942 (1995)

29. Nishio, M., Umezawa, Y., Hirota, M., Takeuchi, Y.: The $\mathrm{CH} / \pi$ interaction: significance in molecular recognition. Tetrahedron. 51, 8665-8701 (1995)

30. Stumpfe, D., Bajorath, J.: Exploring Activity Cliffs in Medicinal Chemistry. J. Med. Chem. 55, 2932-2942 (2012).

31. Stumpfe, D., Hu, Y., Dimova, D., Bajorath, J.: Recent Progress in Understanding Activity Cliff s and Their Utility in Medicinal Chemistry. J. Med. Chem. 57, 18-28 (2014).

32. Neel, A.J., Hilton, M.J., Sigman, M.S., Toste, F.D.: Review Exploiting non-covalent $\pi$ interactions for catalyst design. Nature. 543, 637-646 (2017).

33. 1A free software for NMR analysis of molecular systems undergoing chemical exchange, Mestrelab Research, Chemistry Software solutions

34. Lahore, S., Narkhede, U., Merlini, L., Dallavalle, S.: Total Synthesis of the Natural Product Benzo[j]fluoranthene-4,9diol: An Approach to the Synthesis of Oxygenated Benzo[j]fluoranthenes. J. Org. Chem. 78, 10860-10866 (2013)

35. Sun, Z., Huang, K., Wu, J.: Soluble and Stable Zethrenebis ( dicarboximide ) and Its Quinone. Org. Lett. 12, $4690-4693$ (2010) 